\title{
RETINOPATHY OF PREMATURITY - UPDATE ON SCREENING, TREATMENT, RECENT STUDIES AND LONG-TERM OUTCOMES
}

\author{
J. M. Pfeil, M.-Chr. Bründer, M. Grundel, B. Grundel, A. Stahl \\ Department of Ophthalmology, University Medicine Greifswald - Greifswald, Germany
}

\begin{abstract}
Retinopathy of prematurity, short ROP, is still one of the leading causes of childhood blindness worldwide. The management of ROP, however, has changed tremendously during the last years. This article summarizes known risk factors for ROP, preventive measures and the updated version of the German recommendations for ROP-screening and treatment. A special focus is laid on new treatment options, in particular anti-VEGF treatment, as well as the post-operative and long-term follow-up after treatment. This article also emphasizes the need for joint data collection on an international level and presents the newly-developed initiative for a European wide data collection (EU-ROP) which will be introduced in 2021. All physicians treating ROP infants are welcome to join the EU-ROP initiative.
\end{abstract}

Key words: retinopathy, screening, treatment

\section{РЕТИНОПАТИЯ НА НЕДОНОСЕНОТО - СЪВРЕМЕНЕН ПОДХОД НА СКРИНИНГ И ЛЕЧЕНИЕ. НОВИ ПРОУЧВАНИЯ И ДЪЛГОСРОЧНИ РЕЗУЛТАТИ}

\author{
J. M. Pfeil, M.-Chr. Bründer, M. Grundel, B. Grundel, A. Stahl \\ Катедра по офталмология, Медицински униферситет Грайфсвалд - Грайфсвалд, Германия
}

\section{INTRODUCTION AND STUDY OVERVIEW}

Retinopathy of prematurity (ROP), is an eye disease that mainly affects the most prematurely born and sickest babies. ROP is still one of the leading causes of childhood blindness worldwide. Depending on the level of neonatal care, ROP can also occur in more mature babies.1 Since its first description in 1942 by Terry et al. [2] but especially during the last years, the management of ROP has changed tremendously [3]. First, in the 1950s, the causative association between the rising incidence of ROP and the then usual high oxygen concentrations in incubators was identified [4]. This resulted in the preventive measure of lowering oxygen concentrations, reducing on the one hand the incidence of ROP while increasing on the other hand, unfortunately, the death rate of preterm born infants [5]. The optimal oxygen concentrations to be applied to this vulnerable population is even nowadays unknown, although several interventional clinical trials as well as meta-analyses on the use of oxygen in preterm born infants were conducted in recent years [6-8].

The first prospective clinical trial in the field of ROP was the CRYO-ROP trial, which investigated if cryocoagulation could reduce the risk for developing unfavourable structural outcome in eyes with stage $3+$ in zone I or II in at least 5 contiguous or 8 cumulative clock hours (defined as threshold disease) [9]. Already the preliminary 3-months results were very promising and showed a reduction of the risk of unfavourable outcome from $51.4 \%$ in the natural history group to $31.3 \%$ in the intervention group, which result- 
ed in an adaption of the study protocol to treat all infants with a bilateral zone I disease with cryocoagulation in both eyes (in comparison to a unilateral treatment at the beginning of the trial) [10]. As the final results in 1990 confirmed the preliminary results, cryocoagulation became the first treatment for threshold ROP, although the outcomes were far from optimal [11].

The next big interventional trial was the ETROP (Early Treatment for Retinopathy of Prematurity) trial, in which eyes with a "high-risk" pre-threshold ROP were either treated mainly by laser coagulation at this early stage or managed conventionally (wait and see until an ROP regressed or progressed to threshold disease stages) [12]. The results of the ETROP trial (2004) support the use of laser treatment for any stage of ROP with plus disease in zone I and for zone I stage 3 without plus disease as well as for zone II stages 2 and 3 with plus disease. These treatment criteria from the ETROP trial still form the basis for several national treatment guidelines $[13,14]$.

With the BEAT-ROP (Bevacizumab Eliminates the Angiogenic Threat of ROP) trial the anti-VEGF drug Bevacizumab was first investigated in a prospective randomized controlled trial for zone I or posterior zone II stage 3+ ROP in comparison to laser coagulation. The study found a significantly better outcome after anti-VEGF treatment in eyes with zone I disease compared to laser [15]. It is important to note that one of the main differences between anti-VEGF and laser treatment is that after anti-VEGF treatment, the physiologic vascularization continues to the periphery whereas after laser coagulation, functionless scar tissue develops in the treated areas. Potentially antiVEGF treatment can thus, in addition to halting disease progression reduce the risk of visual field loss for these infants. If the physiologic vascularization after anti-VEGF treatment does not reach the periphery, however, a significant risk of ROP reactivation ensues [15]. Since publication of the BEAT-ROP results in 2011, anti-VEGF treatment for ROP has become a widely used treatment option - despite important unsolved questions particularly regarding long-term safety and dosing [16]. Dose finding studies had not been conducted prior to BEAT-ROP and after publication of BEAT-ROP, most treatment centers adopted the $50 \%$ adult dose of bevacizumab as it has been used in the BEAT-ROP trial. With regard to systemic safety, concern was raised with regard to bevacizumab since it suppresses systemic VEGF levels for weeks after intravitreal injection - a fact that may not be harmful in adult patients but is of unknown significance in a developing organism where several organs still require growth factors for normal growth and development [17].

The CARE-ROP (Comparing Alternative Ranibizumab dosages for safety and efficacy in ROP) trial then tried to answer some of these unsolved questions by investigating lower anti-VEGF doses and with ranibizumab an anti-VEGF compound with significantly shorter systemic half-life (and thus theoretically less effect on systemic VEGF). Both ranibizumab doses used in CARE ROP $(24 \%$ and $40 \%$ of the usual adult dose) were found to be equally effective in controlling acute ROP and did, in contrast to bevacizumab, not alter systemic VEGF levels (results published in 2018) [18]. In the global RAINBOW (Ranibizumab versus laser therapy for the treatment of very low birthweight infants with retinopathy of prematurity) trial (published in 2019) laser coagulation was investigated in comparison to two low doses of ranibizumab $(0.1 \mathrm{mg}$ and $0.2 \mathrm{mg}$ ) confirming that the 0.2 $\mathrm{mg}$ dose ranibizumab is effective in the treatment of ROP and additionally showing that it may even be more effective than laser coagulation.19 Importantly, this was found to be the case not only to the most central ROP zone (zone I), but also for all of zone II disease (both posterior and anterior). An important characteristic of the trial design of both the CARE-ROP as well as the RAINBOW trial was the fact that a re-treatment with the same dose of ranibizumab was allowed if reactivation of treatment requiring ROP was noted after an interval of at least 4 weeks post initial treatment. Such a treatment approach accounts for the fact that some babies might be efficiently treated with one dose of ranibizumab and others might need more antiVEGF (i.e. a re-injection), thus allowing to titrate the appropriate concentration individually per child over time. Since September 2019 ranibizum$\mathrm{ab}$ is approved by the European Medicine Agency in the dose of $0.20 \mathrm{mg}$ for the treatment of ROP zone I stage $1+, 2+, 3+/$ - as well as zone II stage $3+$ and aggressive posterior ROP (AP-ROP) [20].

The PEDIG (pediatric eye disease investigator group) trial investigated how low the dosing of 
anti-VEGF drugs in ROP treatment can go without losing its effect. The study found in 2017 that bevacizumab at $2.5 \%$ of the adult concentration (0.031 mg) was still able to effectively treat ROP [21]. In several of the lower dose arms, however, re-treatments were frequently necessary and it needs to be mentioned that bevacizumab needs to be diluted for such treatment approaches, adding some difficulties for applying this in clinical reality. Bevacizumab at any dose remains an offlabel treatment for ROP.

At the moment, the FIREFLEYE trial is ongoing, in which aflibercept, another anti-VEGF compound, is compared against laser treatment in a global phase III trial [22]. The initial results of this trial are awaited for 2021.

Apart from ROP treatment other initiatives are currently underway and have the potential to change the way we diagnose and treat ROP. For example, a phase II trial investigated if continuous application of rhIGF-1/rhIGFBP-3 from birth to the age of 29 weeks of postmenstrual age would reduce the incidence of ROP in babies born between 23 and 27 weeks GA [23]. Another trial investigated the effect of polyunsaturated fatty acids on the risk of ROP [24]. Both these treatment approaches are based on theoretic considerations and results from animal studies and are worthwhile pursuing. Other trials are focusing on propranolol as preventive treatment for ROP, based on promising initial results from pilot trials but in need of large-scale validation. Beyond ROP treatment and prevention, we will see a new ROP nomenclature, ICROP 3, being published in 2021 taking into account the new forms of the disease we see after anti-VEGF therapy (namely regression and reactivation). We have in recent months also seen important progress in diagnosing and grading ROP with the help of artificial intelligence $[25,26]$ and we have seen ROP severity scores being developed to better compare ROP disease severity during the course of an individual disease $[27,28]$.

\section{RISK FACTORS FOR DEVELOPING ROP AND PREVENTIVE MEASURES}

Certain parameters around birth and during neonatal care increase the risk for ROP [29]. Especially gestational age and birth weight are two well-known factors driving ROP risk [30]. The earlier and the less mature a baby is born the higher is the risk to develop ROP. High levels and fluctuating levels of postnatal oxygen supplementation [31], long-term parenteral nutrition [32], repeated red blood cell transfusions [33], and sepsis [33] as well as a generally unstable postnatal clinical course are all parameters that increase the risk for developing an ROP.

In order to prevent an infant from developing treatment requiring ROP, certain measures can be undertaken: For example, antenatal steroids can be given to the mother to improve lung maturation before preterm birth [34]. As oxygen is the most important modifiable risk factor for developing ROP but on the other hand necessary for the babies to survive without long-term disabilities, careful management of postnatal oxygen including training of involved experts, appropriate equipment, guidelines and a sufficient number of trained personnel is essential [35]. Continuously working on the improvement of neonatal care including reduction of infection rates and blood sampling are additional measures that can be taken. Optimizing postnatal nutrition including the introduction of breastmilk as early as possible, support of breastfeeding in general, as well as a focus on developmental care and skin-to-skincontact are also known preventive measures for unfavourable postnatal developments including ROP $[36,37]$.

\section{ROP-SCREENING CRITERIA}

ROP screening criteria are different around the world depending on which evidence base (e.g. ETROP or the CRYO-ROP trial, or national characteristics of babies who develop ROP requiring treatment) is chosen. Depending on the specific national guideline, different gestational ages and different birthweight criteria are chosen to define who qualifies for ROP screening [38]. These differences between national screening criteria are sensible as they reflect the existing neonatal characteristics in the respective countries.

A treatment requiring ROP that is not treated, is sight threatening for the child and negatively affects the whole life of these children and their families. Therefore, all babies that are at risk of developing a sight threatening ROP need to 
be included in ROP screening measures. On the other hand, as few children as possible who do not develop the need for ROP treatment should be included as the screening procedure is stressful for the child and binds valuable healthcare resources. It is important to define the best possible balance between screening every child at risk for ROP and avoiding stressful examinations for infants who are not at risk.

Neonatal care continuously develops and thus the characteristics of babies change. Therefore, existing national guidelines need to be reviewed and adapted on a regular basis. The German ROP screening guideline, co-developed by German paediatric and ophthalmologic societies, was recently revised [39]. The updated version including the main changes will be presented below. One of the changes was that the upper gestational age limit for ROP screening was lowered from $\leq 32$ weeks to $\leq 31$ weeks gestational age. This means that now all infants born $\leq 31$ weeks are automatically included in the ROP screening program independent of additional risk factors. Infants between 31 and 32 weeks are no longer screened because data from the German Retina. net ROP Registry found that in Germany these infants are not at risk for ROP (as long as no additional risk factors exist) [40]. In addition to the gestational age criteria, all infants are screened who have a birthweight of $<1500 \mathrm{~g}$, require $>5$ days postnatal oxygen supply or ECMO treatment or who have an otherwise complicated postnatal course [40]. With this adaptation the German guideline now follows the trend in other European countries as well as the American guideline on ROP screening that all have lowered their upper ROP screening age over the recent years. An overview of the updated German screening indications is given in Table 1.

Regarding the timing of the initial and follow-up screening assessments the German ROP screening guideline remained unchanged: The first screening is regularly undertaken during the 6th postnatal week, but not before a postmenstrual age of $31+0$ weeks. Follow-up screening exams are regularly done on a biweekly basis until either there is a treatment indication or until the retina is fully vascularized. The time interval can be adapted depending on the retinal findings observed and can either be shortened to weekly
Table 1. Indications for ROP screening in Germany [39]

\begin{tabular}{|l|l|}
\hline $\begin{array}{l}\text { Gestational age } \\
\text { unknown }\end{array}$ & $\begin{array}{l}\text { All babies with a birthweight } \\
<1500 \text { g, independent of oxygen } \\
\text { supplementation }\end{array}$ \\
\hline $\begin{array}{l}\text { Gestational age }<31+0 \\
\text { weeks }\end{array}$ & $\begin{array}{l}\text { All babies, independent of } \\
\text { oxygen supplementation }\end{array}$ \\
\hline $\begin{array}{l}\text { Gestational age } \geq 31+0 \\
\text { weeks and } \leq 37+0 \\
\text { weeks }\end{array}$ & $\begin{array}{l}\text { Babies with additional risk } \\
\text { factors like postnatal oxygen } \\
\text { supplementation }>5 \text { days } \\
\text { ECMO therapy relevant } \\
\text { concomitant diseases } \\
\text { (e.g.: severe necrotizing } \\
\text { enterocolitis, bronchopul- } \\
\text { monary dysplasia, sepsis, } \\
\text { anaemia requiring transfusion) }\end{array}$ \\
\hline
\end{tabular}

intervals or shorter (for example if ROP in zone I or posterior zone II is present or if stage 2 or 3 without plus disease is observed), or it can be expanded to longer intervals of up to three weeks (for example if ROP in zone III is observed and no signs of ROP are present). Follow-up screening exams can be discontinued when the vascularization reaches the ora serrata and the expected date of delivery is achieved (and if no treatment has occurred - after treatment, follow-up exams have to continue longer, see below).

\section{TREATMENT OF ROP}

The updated German guidelines for screening and treating ROP now advises for most of the treatment requiring stages of ROP either antiVEGF injection or laser coagulation (see Table 2) [39]. Only stages 4 and 5 are recommended to be treated with retinal surgery instead. One of the novelties in the revised treatment indication is that in eyes with stage $3+$ in zone II treatment can be initiated if only one clock hour is affected by stage 3 disease. This used to be more conservative in previous versions of the guideline. The second novelty is that after ranibizumab became approved for ROP treatment in Europe by the end of 2019, this treatment modality is now also included in the German treatment recommendation [41].

When a decision between laser photocoagulation and anti-VEGF injection must be made, all positive and negative aspects of the two treatment options need to be considered: laser photocoagulation carries no risk for an endophthalmitis and 
usually does not lead to late reactivations after treatment. It does however, turn retinal tissue into functionless scar tissue, takes longer time under anesthesia to administer treatment and is associated with a higher prevalence of high myopia. Anti-VEGF can be done under local anesthesia or with a short analgosedation, leads to faster treatment effects (which may be advantageous in particularly aggressive cases), does not destroy viable retinal tissue and is associated with lower rates of high myopia. It does however require longer follow-up exams at frequent intervals due to the risk of late reactivations [42]. Table 2 summarizes the advantages and disadvantages of laser photocoagulation as well as anti-VEGF treatment.

Other treatment options like cryocoagulation are no longer recommended except for maybe very special cases where both anti-VEGF and laser treatment cannot be applied.

Table 3 gives an overview over the treatment recommendations depending to the different treatment indications according to the current German guideline [41].

\section{POST-OPERATIVE FOLLOW-UP}

The recommended procedure of post-operative follow-up visits depends on the treatment method. After laser coagulation, weekly assessments should take place until a significant reduction of ROP activity is seen and it is ensured that confluent laser scars cover all avascular retinal areas. If this is the case, the follow-up intervals can be expanded and continued until a stable stage of ROP without any active proliferations, retinal tractions or plus disease is achieved. After anti-VEGF treatment, the first assessment should take place within four days after treatment in order to rule out any potential treatment associated complications like endophthalmitis. The following visits should then be scheduled according to the retinal findings and the recommendations for ROP screening before treatment (see above). Different to both laser treated eyes and untreated eyes, follow-up exams after anti-VEGF treatment must continue for a longer time at frequent intervals. Peripheral avascular areas can lead to late reactivations through the expression of VEGF that is no longer inactivated by anti-VEGF molecules once these have left the eye into the circulation. The timeframe how fast
Table 2. Comparison of the advantages and disadvantages of laser photocoagulation and anti-VEGF therapy (adapted from M. Grundel [42])

\begin{tabular}{|l|l|}
\hline Laser photocoagulation \\
\hline Advantages: & $\begin{array}{l}\text { No intraocular procedure and therefore } \\
\text { no risk of endophthalmitis } \\
\text { Usually complete photocoagulation of } \\
\text { avascular areas in one treatment }\end{array}$ \\
\hline Disadvantages: & $\begin{array}{l}\text { Lengthy procedure, which usually } \\
\text { requires general anesthesia } \\
\text { High expertise of the treating physician } \\
\text { required } \\
\text { Longer duration until the therapeutic } \\
\text { effect is achieved } \\
\text { Irreversible destruction of retinal } \\
\text { tissue resulting in possible visual field } \\
\text { restrictions }\end{array}$ \\
\hline Anti-VEGF treatment \\
\hline Advantages: & $\begin{array}{l}\text { Fast treatment procedure } \\
\text { Treatment possible without general } \\
\text { anesthesia } \\
\text { No destruction of retinal tissue, } \\
\text { physiologic vascularization can continue } \\
\text { Lower rate of high myopia }\end{array}$ \\
\hline Disadvantages: & $\begin{array}{l}\text { Intraocular procedure with risk for } \\
\text { endophthalmitis } \\
\text { Intraocular drug levels decrease over } \\
\text { time leading to potential risk of late ROP } \\
\text { reactivation } \\
\text { Frequent long-term follow-up } \\
\text { assessments necessary to detect } \\
\text { potential late reactivations } \\
\text { Some anti-VEGF agents are known to } \\
\text { influence the systemic VEGF levels over a } \\
\text { long period of time } \\
\text { As VEGF inhibitors are relatively new in } \\
\text { the treatment of RoP only limited long- } \\
\text { term data exists }\end{array}$ \\
\hline
\end{tabular}

Table 3. Treatment indications according to the current German guideline on treating ROP

\begin{tabular}{|l|l|l|l|}
\hline Zone & Stage & $\begin{array}{l}\text { Plus- } \\
\text { disease }\end{array}$ & $\begin{array}{l}\text { Treatment } \\
\text { recommendation }\end{array}$ \\
\hline I & $1,2,3$ & + & $\begin{array}{l}\text { Anti-VEGF or laser } \\
\text { coagulation }\end{array}$ \\
\hline I & 3 & - & $\begin{array}{l}\text { Anti-VEGF or laser } \\
\text { coagulation }\end{array}$ \\
\hline I/II & Aggressive ROP & + & $\begin{array}{l}\text { Anti-VEGF or } \\
\text { laser coagulation } \\
\text { (treatment sometimes } \\
\text { necessary within 24 } \\
\text { hours after diagnosis) }\end{array}$ \\
\hline II & $\begin{array}{l}3 \text { (new: already } \\
\text { when only one } \\
\text { clock hours is } \\
\text { affected) }\end{array}$ & + & $\begin{array}{l}\text { Anti-VEGF or laser } \\
\text { coagulation }\end{array}$ \\
\hline III & $1,2,3$ & & Usually no treatment \\
\hline Stage 4 or 5 & $+/-$ & Retinal surgery \\
\hline
\end{tabular}


this happens may differ from infant to infant. It is important to acknowledge that a reactivation of treatment requiring ROP can occur even several months after anti-VEGF treatment $[43,44]$. The literature describes late recurrences of active ROP up to 7 months after treatment $[43,45]$. In case regular follow-up exams cannot be guaranteed, laser photocoagulation of remaining avascular areas can be the best option.

\section{LONG-TERM OUTCOMES AFTER TREATMENT}

If not treated timely, an ROP can still today be a sight threatening disease. Laser coagulation has been standard of care since the results of the ETROP trial were published, which is not even 20 years ago [12]. The BEAT-ROP trial published their initial results in 2011 [15]. The compounded data on long-term outcomes after treatment of ROP is thus not very large. It is described that after laser coagulation the risk for developing high myopia is considerably higher than after anti-VEGF treatment [46]. The risk for a late reactivation of ROP, in contrast, is higher after antiVEGF treatment and may also occur much later than after laser coagulation [45]. A retrospective analysis from Morin et al. reported poorer neurodevelopmental outcomes after anti-VEGF treatment than after laser coagulation [47]. This analysis, however, needs to be interpreted with caution as for example in the bevacizumab group the percentage of infants with a zone I disease was higher than in the laser arm, which might be a sign of unequal distribution between the study groups. Long-term outcomes from the CARE-ROP and the RAINBOW trials are expected in 2021.

\section{DATA-COLLECTION}

Most hospitals where treatment for ROP is performed, have relatively low treatment numbers per year. While this is a good sign in general, it makes data collection and interpretation very difficult and prone to bias and error. We have therefore in 2012 established the German Retina. net ROP registry to combine data from as many centers as possible and collectively analyze our ROP treatment data $[16,48]$. Until now data from more than 600 treated eyes was entered into the database. Many decisions in the updated German screening and treatment guidelines were influenced by evidence from this registry data. We are currently in the process of expanding this German registry into an international database and would be very happy to include centers from as many countries as possible. Only in a combined effort will it be possible to yield strong and reliable data for future treatment and guideline decisions (see Figure 1 for the logo of the European wide ROP registry project EU-ROP that will be launched in 2021). Centers or individual experts treating ROP are very welcome to contact the authors for participation in this project.

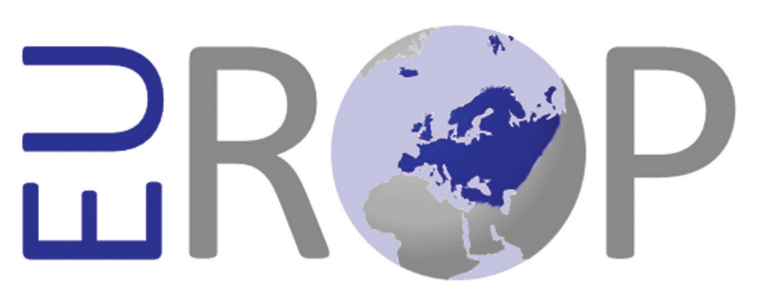

Fig. 1. The EU-ROP project will be launched in 2021 as a registry project to collect and analyze data from treated ROP infants across different European countries. All centers treating ROP are invited to join this project and contribute their treatment data for joint analysis and publication.

\section{ConClusion}

Recommendations for ROP screening and treatment have both changed over the recent years. New treatment options, like anti-VEGF treatment, can be useful alternatives if applied carefully and with sufficient long-term follow-up. In order to further improve the management of ROP, a joint effort to collect real world data on a national as well as an international level will be necessary. The EU-ROP registry initiative invites participants to contribute their ROP treatment data to this joint effort. More data can be obtained from the website www.eu-rop.org.

\section{REFERENCES}

1. Quinn GE. Retinopathy of prematurity blindness worldwide: phenotypes in the third epidemic. Eye Brain. 2016;8:31-36. doi:10.2147/EB.S94436.

2. TerryTL.ExtremePrematurity and Fibroblastic Overgrowth of Persistent Vascular Sheath Behind Each Crystalline Lens. Am J Ophthalmol. 1942;25(2):203204. doi:10.1016/S0002-9394(42)92088-9.

3. Hellström A, Hård A-L. Screening and novel therapies for retinopathy of prematurity - A review. Early Hum Dev. 2019;138:104846. doi:10.1016/j. earlhumdev.2019.104846. 
4. Patz A. The role of oxygen in retrolental fibroplasia. Trans Am Ophthalmol Soc. 1968;66:940-985.

5. Campbell K. Intensive oxygen therapy as a possible cause of retrolental fibroplasia; a clinical approach. Med J Aust. 1951;2(2):48-50.

6. BOOST II United Kingdom Collaborative Group, B00ST II Australia Collaborative Group, BO0ST II New Zealand Collaborative Group, et al. Oxygen saturation and outcomes in preterm infants. N Engl J Med. 2013;368(22):2094-2104. doi:10.1056/NEJMoa1302298.

7. Schmidt B, Asztalos EV, Roberts RS, et al. Impact of bronchopulmonary dysplasia, brain injury, and severe retinopathy on the outcome of extremely low-birth-weight infants at 18 months: results from the trial of indomethacin prophylaxis in preterms. JAMA. 2003;289(9):1124-1129. doi:10.1001/jama.289.9.1124.

8. Askie LM, Henderson-Smart DJ, Ko H. Restricted versus liberal oxygen exposure for preventing morbidity and mortality in preterm or low birth weight infants. Cochrane Database Syst Rev. 2009;(1):CD001077. doi:10.1002/14651858. CD001077.pub2.

9. Cryotherapy for Retinopathy of Prematurity Cooperative G. Multicenter trial of cryotherapy for retinopathy of prematurity. Snellen visual acuity and structural outcome at $51 / 2$ years after randomization. Arch Ophthalmol. 1996;114(4):417424.

10. Multicenter trial of cryotherapy for retinopathy of prematurity. Three-month outcome. Cryotherapy for Retinopathy of Prematurity Cooperative Group. Arch Ophthalmol. 1990;108(2):195-204.

11. Palmer EA. Results of U.S. randomized clinical trial of cryotherapy for ROP (CRYO-ROP). Doc Ophthalmol Adv Ophthalmol. 1990;74(3):245-251. doi:10.1007/BF02482615.

12. Good WV, Early Treatment for Retinopathy of Prematurity Cooperative Group. Final results of the Early Treatment for Retinopathy of Prematurity (ETROP) randomized trial. Trans Am Ophthalmol Soc. 2004;102:233-248; discussion 248-250.

13. Fierson WM. American Academy of Pediatrics Section On Ophthalmology, American Academy Of Ophthalmology, American Association For Pediatric Ophthalmology And Strabismus, American Association Of Certified Orthoptists. Screening Examination of Premature Infants for Retinopathy of Prematurity. Pediatrics. 2018;142(6):e20183061. doi:10.1542/peds.2018-3061.

14. Sydney Local Health District. SLHD: Royal Prince Alfred Hospital Guideline: Women and Babies: Retinopathy of Prematurity.; 2018. https://www. slhd.nsw.gov.au/RPA/neonatal\%5Ccontent/pdf/ guidelines/RPAH_GL2018_006_ROP_final.pdf.

15. Mintz-Hittner HA, Kennedy KA, Chuang AZ, et al. Efficacy of intravitreal bevacizumab for stage $3+$ retinopathy of prematurity. $\mathrm{N}$ Engl J Med. 2011;364(7):603-615. doi:10.1056/NEJMoa1007374.

16. Walz JM, Bemme S, Pielen A, et al. The German ROP Registry: data from 90 infants treated for retinopathy of prematurity. Acta Ophthalmol. Published online May 20, 2016. doi:10.1111/aos.13069.

17. Sato T, Wada K, Arahori H, et al. Serum concentrations of bevacizumab (avastin) and vascular endothelial growth factor in infants with retinopathy of prematurity. Am J Ophthalmol. 2012;153(2):327333 e1. doi:10.1016/j.ajo.2011.07.005.

18. Stahl A, Krohne TU, Eter N, et al. Comparing alternative ranibizumab dosages for safety and efficacy in retinopathy of prematurity: A randomized clinical trial. JAMA Pediatr. Published online January 8, 2018. doi:10.1001/jamapediatrics.2017.4838.

19. Stahl A, Lepore D, Fielder A, et al. Ranibizumab versus laser therapy for the treatment of very low birthweight infants with retinopathy of prematurity (RAINBOW): an open-label randomised controlled trial. The Lancet. 2019;394(10208):15511559. doi:10.1016/S0140-6736(19)31344-3.

20. EMA.Europa.eu. Lucentis $10 \mathrm{mg} / \mathrm{ml}$ solution for injection SmPC. Published online January 28, 2020. Accessed August 27, 2020. https://www. ema.europa.eu/en/documents/product-information/lucentis-epar-product-information_en.pdf.

21. Wallace DK, Kraker RT, Freedman SF, et al. Assessment of Lower Doses of Intravitreous Bevacizumab for Retinopathy of Prematurity: A Phase 1 Dosing Study. JAMA Ophthalmol. Published online April 27, 2017. doi:10.1001/jamaophthalmol.2017.1055.

22. Clinicaltrials.gov. Aflibercept for Retinopathy of Prematurity - Intravitreal Injection Versus Laser Therapy (FIREFLEYE). www.clinicaltrials.gov. Published November 10, 2020. https://clinicaltrials.gov/ct2/show/NCT04004208?cond=ROP\&dr $\mathrm{aw}=2$ \&rank=3.

23. Ley D, Hallberg B, Hansen-Pupp I, et al. rhIGF-1/ rhIGFBP-3 in Preterm Infants: A Phase 2 Randomized Controlled Trial. J Pediatr. 2019;206:56-65. e8. doi:10.1016/j.jpeds.2018.10.033.

24. Pawlik D, Lauterbach R, Walczak $M$ et al. Fishoil fat emulsion supplementation reduces the risk of retinopathy in very low birth weight infants: a prospective, randomized study. JPEN J Parenter Enteral Nutr. 2014;38(6):711-716. doi:10.1177/0148607113499373.

25. Gensure RH, Chiang MF, Campbell JP. Artificial intelligence for retinopathy of prematurity. Curr Opin Ophthalmol. 2020;31(5):312-317. doi:10.1097/ICU.0000000000000680.

26. Scruggs BA, Chan RVP, Kalpathy-Cramer J et al. Artificial Intelligence in Retinopathy of Prematurity Diagnosis. Transl Vis Sci Technol. 2020;9(2):5. doi:10.1167/tvst.9.2.5. 
27. Smith LEH, Hellström A, Stahl A, et al. Development of a Retinopathy of Prematurity Activity Scale and Clinical Outcome Measures for Use in Clinical Trials. JAMA Ophthalmol. 2019;137(3):305-311. doi:10.1001/jamaophthalmol.2018.5984.

28. Pivodic A, Nilsson S, Stahl A et al. Validation of the Retinopathy of Prematurity Activity Scale (ROP-ActS) using retrospective clinical data. Acta Ophthalmol (Copenh). Published online June 26, 2020:aos.14532. doi:10.1111/aos.14532.

29. Hellström A, Smith LE, Dammann O. Retinopathy of prematurity. The Lancet. 2013;382(9902):14451457. doi:10.1016/S0140-6736(13)60178-6.

30. Darlow BA, Hutchinson JL, Henderson-Smart DJ et al. Prenatal risk factors for severe retinopathy of prematurity among very preterm infants of the Australian and New Zealand Neonatal Network. Pediatrics. 2005;115(4):990-996. doi:10.1542/ peds.2004-1309.

31. York JR, Landers S, Kirby RS et al. Arterial oxygen fluctuation and retinopathy of prematurity in very-low-birth-weight infants. J Perinatol Off J Calif Perinat Assoc. 2004;24(2):82-87. doi:10.1038/ sj.jp.7211040.

32. Vanhaesebrouck S, Vanhole C, Zegher F d., Allegaert $\mathrm{K}$. Influence of duration of parenteral nutrition on retinopathy of prematurity. Arch Dis Child - Fetal Neonatal Ed. 2007;93(2):F170-F170. doi:10.1136/adc.2007.128991.

33. Chang JW. Risk factor analysis for the development and progression of retinopathy of prematurity. Hansen RM, ed. PLOS ONE. 2019;14(7):e0219934. doi:10.1371/journal.pone.0219934.

34. Yim C-L, Tam M, Chan H-L et al. Association of antenatal steroid and risk of retinopathy of prematurity: a systematic review and meta-analysis. Br J Ophthalmol. 2018;102(10):1336-1341. doi:10.1136/bjophthalmol-2017-311576.

35. EFCNI, Hellström A, Hellström-Westas L. Prevention, detection, documentation, and treatment of retinopathy of prematurity (ROP). Published online 2018.

36. Porcelli PJ, Weaver RG. The influence of early postnatal nutrition on retinopathy of prematurity in extremely low birth weight infants. Early Hum Dev. 2010;86(6):391-396. doi:10.1016/j.earlhumdev.2010.05.015

37. Lenhartova N, Matasova K, Lasabova Z et al. Impact of early aggressive nutrition on retinal development in premature infants. Physiol Res. 2017;66(Suppl 2):S215-S226. doi:10.33549/physiolres.933677.

38. Mora JS, Waite C, Gilbert CE et al. A worldwide survey of retinopathy of prematurity screening.
Br J Ophthalmol. 2018;102(1):9-13. doi:10.1136/ bjophthalmol-2017-310709.

39. Maier RF, Hummler H, Kellner U et al. Augenärztliche Screening-Untersuchung bei Frühgeborenen AWMF-Leitlinien-Register Nr. 024/010. Published online 2020.

40. Larsen P, Bründer M, Petrak M et al. Screening for retinopathy of prematurity: Trends over the past five years in two German university centers. Ophthalmologe. 2018;115(6). In press.

41. Deutsche Ophthalmologische Gesellschaft e.V. (DOG), Retinologische Gesellschaft e.V. (RG), Berufsverband der Augenärzte Deutschlands e.V. (BVA). Stellungnahme der Deutschen Ophthalmologischen Gesellschaft, der Retinologischen Gesellschaft und des Berufsverbands der Augenärzte Deutschlands zur Anti-VEGF-Therapie der Frühgeborenenretinopathie: Stand: 18.05.2020. Ophthalmol. Published online July 21, 2020. doi:10.1007/ s00347-020-01170-x.

42. Grundel M, Bründer M-C, Stahl A, Grundel B. Therapie der Frühgeborenenretinopathie. Published online in preparation.

43. Mintz-Hittner HA, Geloneck MM, Chuang AZ. Clinical Management of Recurrent Retinopathy of Prematurity after Intravitreal Bevacizumab Monotherapy. Ophthalmology. 2016;123(9):18451855. doi:10.1016/j.ophtha.2016.04.028.

44. Lyu J, Zhang Q Chen C-L et al. Recurrence of Retinopathy of Prematurity After Intravitreal Ranibizumab Monotherapy: Timing and Risk Factors. Invest Ophthalmol Vis Sci. 2017;58(3):1719-1725. doi:10.1167/iovs.16-20680.

45. $\mathrm{Hu}$ J, Blair MP, Shapiro MJ et al. Reactivation of retinopathy of prematurity after bevacizumab injection. Arch Ophthalmol Chic Ill 1960. 2012;130(8):1000-1006. doi:10.1001/archophthalmol.2012.592.

46. Geloneck MM, Chuang AZ, Clark WL,et al. Refractive outcomes following bevacizumab monotherapy compared with conventional laser treatment: a randomized clinical trial. JAMA Ophthalmol. 2014;132(11):1327-1333. doi:10.1001/jamaophthalmol.2014.2772.

47. Morin J, Luu TM, Superstein R et al. Neurodevelopmental Outcomes Following Bevacizumab Injections for Retinopathy of Prematurity. Pediatrics. 2016;137(4). doi:10.1542/peds.2015-3218.

48. Walz JM, Bemme S, Reichl S et al. [Treated cases of retinopathy of prematurity in Germany : 5-year data from the Retina.net ROP registry]. Ophthalmol Z Dtsch Ophthalmol Ges. 2018;115(6):476488. doi:10.1007/s00347-018-0701-5. 